\title{
DIF PLEK VAN DIF SWAARDMagorganisasie (WEERMAG) IN DIE STAATSBESTEL
}

\author{
Kmoli J. F, J. KIRSTEN *
}

\begin{abstract}
The writer discusses the position of the armed forces within the State from a philosophical point of view. He sketches the changing philosophical approach to the role of the armed forces from the Middle Ages onwards.
\end{abstract}

\section{Inleiding}

In die menslike samelewingsorde word tussen drie hooftipes van lewensvorme onderskei, naamlik verband- gemeenskap-en maatskapstrukture. ${ }^{1}$ Die verbandstruktuur word gekenmerk deur 'n interne, solidêre eenheidskarakter, onafhanklik van die wisseling van sy lede, met ' $n$ permanente gesagsverhouding en wel in ' $n$ posisie van bowe- en onderskikking. ${ }^{2}$ Hierdie twee strukturele eienskappe tipeer alle verbande, waaronder, naas die staat ook die gesin en kerk sorteer. Die gemeenskapstrukture openbaar slegs één van hierdie eienskappe, soos by huwelik, familie en volk. ${ }^{3}$ In die maatskapstrukture bestaan ' $n$ neweskikkende ordening soos by vriendskap en buurskap, ${ }^{4}$ en 'n permanente gesagstruktuur is ondenkbaar.

Ons let vervolgens daarop dat die staatsverband hom van die ander verbande onderskei, en ons speur die owerheidsgesag na, ten einde die basis vir hierdie artikel te kry.

\section{Struktuur van die staatsverband}

Soos reeds geponeer, laat die staat hom as 'n verband tipeer vanweë sy solidêre eenheidskarakter en die permanente gesagstruktuur, soos geopenbaar in die verhouding owerheid tot onderdaan.

Daar is egter ook nog ander verbandstrukture, soos kerk en gesin, en daarom die onderskeiding van hierdie verbande. Vooraf moet ons die unieke onderbou (funderingsfunksie) en bobou (bestemmingsfunksie) van die staatsverband aandui.

\section{Die funderingsfunksie van die staatsverband}

Die staatsverband is in die historiese wetskring gefundeer, ${ }^{5}$ waarvan die grondwet beskawingsontwikkeling is ${ }^{6}$ dit wil sê beheersende vorming van 'n gegewe aanleg, struktuur of toestand tot iets wat nie vanself ontwikkel of ontstaan nie, maar wat slegs deur die mens in sy normatiewe vry. heid verwerklik word.?
Met die uitsondering van enkele lewensvorme soos die gesin, familie en volk wat histories-bioties gefundeer is, is alle ander in die historiese wetskring gefundeer. Die fundering van die staatsverband onderskei hom van laasgenoemde lewensvorme daarin dat ook slegs die staat in die historiese swaardmag gefundeer is. ${ }^{8}$ Dat die staatsverband sy fundering in die historiese wetskring het, word tewens bewys uit alle staatstigtings. Dit is ' $n$ verbandstruktuur waar die normatiewe vryheid bewus aangewend word, soos wat blyk uit die verskillende organisatoriese manifestasies daarvan. Die tipiese staatlike eienskap, wat in die veelheid van staatsvorme egter kenbaar is, is die swaardmag, monopoisties georganiseer op ' $n$ bepaalde territorium. ${ }^{9}$

Omdat die funksie normatief en taakstellend ${ }^{10}$ van aard is, is dit die roeping van die owerheid om die swaardmag op so ' $n$ wyse te organiseer dat die staatsverband sy normatiewe individualiteitstruktuur na binne en na buite kan openbaar. Daar was nog nooit ' $n$ staat waarvan die interne struktuur, in die laaste instansie, nie op 'n georganiseerde gewapende mag gebaseer was nie; of wat nie ten minste in staat was om enige gewapende weerstand van privaat persone of organisasies binne sy gebied die hoof te bied nie."1 Die staat wat die organisasie van sy swaaramag verwaarloos, ondermyn sy eie identiteit en grawe daardeur sy eie graf. ${ }^{12}$

${ }^{*}$ Kmdt. J.F.J. Kirsten is Senior Lektor in Publieke Administrasie en Staatsleer aan die Militêre:Akademie, Saldanha.

1. Vergelyk H.J. Strauss: Christelike Wetenskap en Christe like Onderwys, (Bloemfontein, 1964), p 36.

2. Vergelyk J.M. Spier: Inleiding in de Wijsbegeerte de Wetsidee, (Kampen, 1950) p 176.

3. Vergelyk J.M. Spier: op cit., p 177

4. Ibid.

5. Vergelyk $H$. Dooyeweerd: A new critique of Theore tical Thought, soos vertaal deur D.H. Freeman and $\mathrm{H}$. de Jongste, (Paris-Amsterdam, 1957) p 423

6. Vergelyk J.M. Spier: W. der W. p 82.

7. Ibid

8. Ibid, p 203

9. Vergelyk H. Dooyeweerd: op cit., p414 ... 'an internal monopolistic organisation of the power of the sword over a particular cultural area within territorial boundaries.'

10. Ibid.

11. Ibid.

12. Vergelyk J.M. Spier: $W$. der W., p203. 
Hierdie swaardmag van die staat moet in sy goddelike institutêre'struktuur verstaan word alvorens oor die werklike subjektiewe wyse, waarop dit hanteer word, geoordeel word. ${ }^{13}$ Instelling van die swaardmag by die verbond met Noag word van teologiese kant geponeer. ${ }^{14}$ Immers die opname van die swaardmag in sy samehang met die leidende funksie van die staat, is slegs vanweë die sonde in die tydelike wêreldorde te begryp. ${ }^{15}$ Omdat Thomas Aquinas die staat in die natuur van die mens gefundeer het, sien hy die swaardmag van die owerheid slegs in die lig van die sonde, met ander woorde, 'n dwingende mag behorende tot die relatiewe natuurreg. ${ }^{16}$ Die swaardmagorganisasie van 'n staat openbaar bowendien 'n heenwysende struktuur, wat nie in terme van blote gewapende beheer verklaar kan word nie. ${ }^{17}$ Dit is en bly egter ons oortuiging dat die normatiewe individualiteit van die staatsverband ook in die swaardmagorganisasie weerspieël word.

Humanistiese sowel as die Christelike staatsfilosowe het besliste standpunte ten opsigte van die swaardmagorganisasie gehuldig, en derhalwe let ons vervolgens daarop. Met die verval van die Middeleeuse eenheidskultuur vertak die humanistiese denke in twee hoofrigtings, enersyds vorsabsolutisme waarby die opkoms van die nasionale monargieë veel sal baat en andersyds volksoewereiniteit, wat die demokrasieë, onder dwang van die mondigwordende individu, weer sou beïnvloed. ${ }^{18}$

Van die soewereine staat is daar in die universalistiese eenheidsgedagte van die Middeleeue geen sprake nie, daar dit die onbetwisbare oppergesag van die Pous bevestig het. 'n Teoretiese regverdiging vir die keiserlike gesag sal eers verkry moet word en eers wanneer dit bo alle twyfel gevestig is, kan die regstaat gevorm word. Die konsentrasie van gesag en swaardmag in die nasionale staat sou eers volg na ' $n$ besliste verbreking van die pouslike oppergesag, en as vorsabsolutisme in die nasionale monargie stewig gevestig is, word medeseggenskap van 'n mondige burgery 'n voorvereiste vir. 'n nasionale harmonie. Die opkoms van die 'nasionale magstate eis vir hulself ' $n$ teoretiese regverdiging teen die pouslike sowel as die keiserlike wêreldheerskappy. ${ }^{19}$

In die opkomende nasionale landstate is gesagsen swaardmagkonsentrasie die uitstaande kenmerk. Nasionalisme ontluik en nasionaliteit word 'n indelingsmaatstaf vir die state-verskeidenheid.

State wat hulself bowendien as gevolg van die toename van die tegniese en ekonomiese ontwikkeling meer en meer met die lewe van die staatsvolk moet bemoei. 'n Positiewe publiekregsorde, die handhawing van die ewewig en harmonie in die aanwassende veelheid van regsbelange word meer aktueel. 20

Die gesagkonsentrasie van die magstaat was onontbeerlik vir die konsolidering van die nasionale state en die staatlike monopolie oor die swaardmag. ${ }^{21}$

Machiavelli as tipiese verteenwoordiger van die Humanisme uit die 15de en 16 de eeu het ' $n$ besondere belangstelling vir militêre aangeleenthede, soos sy werk Arte della Guerra ${ }^{22}$ getuig. Hy het militêre sake nie as militêre tegnikus of deskundige benader nie, maar wel uit 'n politieke oogpunt, daarom het hy gesê dat die belangrikheid en grootheid van 'n staat slegs gemeet kan word aan die plek wat die swaardmagorganisasie in die politieke orde inneem. ${ }^{23}$ Een van Machiavelli se stellinge waaraan hy baie waarde geheg het, was dat 'n goed georganiseerde swaardmag doeltreffende wette waarborg. 'n Staat met 'n sterk swaardmagorganisasie beskik vir hom ook vanselfsprekend oor 'n goeie regstelsel. ${ }^{24}$

In sy geskrifte herinner Machiavelli die regeerders van sy tyd daaraan dat hulle mag en gesag op die sterkte van hul swaardmagorganisasie berus. ${ }^{25} \mathrm{Hy}$ poneer verder dat die fondament van 'n staat in 'n kragtige en magtige militêre mag geleë is. ${ }^{26}$ Die ondersoek na die rol en invloed van die swaardmag in die politieke lewe was vir Machiavelli 'n sentrale tema waarom hy sy politieke denke gesentreer het. ${ }^{27}$ Daarom verklaar hy dat die militêre organisasie ' $n$ integrale deel van die Middeleeue was in so 'n mate dat dit verval het toe die sosiale struktuur van daardie tyd gedisintegreer het. ${ }^{28}$ Die ridder, as Middeleeuse militaris, was geestelik en ekonomies 'n uitstaande produk van dié tydperk. Hy het

13. Vergelyk F.J.H. Wessels: Die Owerheidstaak, IOngepubliseerde proefskrif aan die Universiteit van die Oranje Vrystaat, Bloemfontein, 1957) p114.

14. Vergelyk $H$. Dooyeweerd: op cit., p423.

15. Ibid. "it would be fundamentally wrong to confuse the fact of this "because of $\sin ^{\prime \prime}$, referring to the institutional office of the military power, with the sinful subjective way in which the power of the sword is handled in a particular state.

16. Vergelyk F.J.H. Wessels: op cit., p114

17. Vergelyk H. Dooyeweerd: op cit., p422.

18. Vergelyk F.J.H. Wessels: V'rouestemreg, p41.

19. Vergelyk H.J. Strauss: Diktaat Staatsleer // (1959)

20. Ibid

21. Ibid.

22. Art of War

23. Vergelyk Earle, Edward, Mead: Makers of Modern Strategy p3

24. Ibid.

25. Ibid

26. Ibid

27. Ibid

28. Ibid. p5 
sy dienste tot die beskikking van sy leenheer (Overlord) gestel. ${ }^{29}$ Machiavelli het voorts die mening gehuldig dat die verskillende vorme van militêre organisasie en die diversiteit van die oorlogsmetodes van die Middeleeue deur drie faktore bepaal is. Eerstens die religieuse konsep dat die oorlog 'n reg. verdigde daad is. ${ }^{*}$ Tweedens dat militêre diens to' die ridders beperk was.

Derdens 'n eties-juridiese kode as enigste bindende maatstaf wat die staande leër konsolideer. ${ }^{30} \mathrm{Om}$ rede oorlogvoering vir hom die vervulling van ' $n$ religieuse en morele taak was, het hy geponeer dat daar 'n sterk neiging was om oorloë en gevegte in ooreenstemming met vaste reëls en bepaalde kodes te voer. ${ }^{31}$

Die tydelike aard van die swaardmagorganisasies sowel as die verskillende oorlogsmetodes het streng dissipline aansienlik bemoeilik of onmoontlik gemaak. Dit was geen seldsame gebeurtenis om twee ridders in 'n geveg tot die dood toe gewikkel te sien nie. Die uitslag van sulke gevegte was dikwels belangrik vir die onderskeie leenhere. As gevolg van hierdie toestand het Machiavelli bo en behalwe die belangrikheid van oorlogvoering ook die klem in die tweede plek op dissipline en orde laat val. ${ }^{32}$ So sê hy dat 'Good order makes men bold and confusion cowards'33 in aanvulling hierby het hy verder verklaar dat 'Few men are brave by nature, but good order and experience make many so. Good order and discipline in an army are more to be depended upon than courage alone. ${ }^{34}$

Hy het gevoel dat aangesien die swaardmag hoofsaaklik vir oorlog georganiseer word, die dissipline van elke soldaat van die hoogste gehalte moet wees. Dit omvat die hoofdoel van die handhawing van dissipline en orde, naamlik om 'n militêre mag voor te berei om die vyand 'n volslae nederlaag toe te dien. ${ }^{35}$ Ten slotte sê Machiavelli dat elke soldaat geleer moet word dat dissipline en goeie orde vir die welslae van enige swaardmagorganisasie onontbeerlik is. ${ }^{36}$ Hieruit blyk duidelik dat die Middeleeue die swaardmagapparaat hoog aanslaan, en 'n plek in die staat gee wat selfs skeef kan ontwikkel. Sover vir die vroeg humanistiese siening van Machiavelli. Laat ons nou die saak van 'n ander hoek benader, naamlik die Christelike staatsfilosofie en sy verwysing na die swaardmagorganisasie.

By Calvyn word 'n radikaal Christelike verweer teen die Middeleeuse of skolastiese-religieuse grondmotief van natuur en genade gevind. Skepping, sondeval en verlossing deur Jesus Christus dra sy hele konsepsie ook ten opsigte van die staat.

Die staat vind sy absolute grond in God die Almag tige, die Skepper en Onderhouer van alle dinge. Die ontstaan van state is deur die voorsienige bestuur van God bepaal; Hy beskik oor die state en sanksioneer die owerhede as gesaghebbend vir die menslike lewe. So gebruik God in sy genadewerk die staat ter bevordering van die aardse heil van die mensheid. As gevolg van die sonde het die staat die swaardmag en die gevolglike dwangkarakter verkry - dit is reeds met sy ontstaan gegee. ${ }^{37}$

Aangesien die historiese funderingsfunksie van die staat egter ook 'n subjek-objekverhouding 38 openbaar, noodsaak dit ons om kortliks die aandag daarop te vestig. Die objek van die swaardmag is geleë in die militêre middele soos wapentuig waarmee die staatsorgane die mag uitoefen. Maar hierdie objektiewe middele het weinig, indien enige, waarde sonder die subjektiewe organisasie van 'n weermag of polisiemag wat die objektiewe middele moet aanwend. 39

Die strukturele subjek-objek verhouding en die funderingsfunksie van die staat is egter nog meer gekompliseerd as wat dit op die oog af wil voorkom. ${ }^{40}$ Dit sluit ook die verhouding tussen die georganiseerde swaardmag en die kulturele territorium van die politieke owerheid41 in. Uit 'n historiese modale oogpunt moet hierdie kulturele area as 'n objek van die magsvorming van die staat gesien word. Uit 'n strukturele oogpunt kan hierdie historiese aspek van die staatsterritorium nooit los van die kwalifiserende judisiële funksie van die staatsverband gesien word nie.42 Hierdie noodwendige verhouding tussen die funderings- en die bestemmingsfunksie is geen grond vir die verontagsaming van die besondere modale betekenis van die funderingsfunksie nie. ${ }^{43}$

29. Ibid.

* 'Just War doctrine' Sien Dougherty and Pfaltzgraff: Contending Theories of International Relations.

30. Vergelyk Earle, Edward, Mead: The makers of Modern Strategy, p 5

31. Ibid.

32. Ibid., p 18

33. Ibid.

34. Ibid.

35. Ibid

36. Ibid.

37. Vergelyk G.H. Sabine: A history of Political Theory, (London, 1964), 1366.

38. Vergelyk J.M. Spier: op. cit., p204.

39. Ibid.

40. Vergelyk H. Dooyeweerd: op cit., p 422

41. Ibid.

42. Ibid. 
Militêre magsorganisasie het in sy historiese modaliteit nie 'n judisiële karakter nie. ${ }^{44}$ Om hierdie rede kan die kader van die staat se swaardmag, as die objek van die subjektiewe formasie van militêre beheer nie in modaal jurisdiese sin aangegryp word nie. ${ }^{45}$

Daar moet gewaak word teen die aanvaarding dat die staatsverband uitsluitlik uit die georganiseerde swaardmag bestaan. ${ }^{46}$ Die swaardmag is wel die magsvorm wat tipies is van die staatslewe, met ander woorde dit word in geen ander lewensvorm gevind nie. ${ }^{47}$ Die staat beskik ook oor 'n ekonomiese geldmag, sedelike en geloofskrag. Trouens sonder hierdie antisiperende magsvorme sou selfs die vorming van 'n weermag onmoontlik wees. Belangrik is dit om op te merk dat alhoewel die staatsverband met ander gekwalifiseerde magsvorme binne sy grense vervleg is, ${ }^{48}$ geen verswakte swaardmagorganisasie bloot op nie-staatlike magsvorme sterk sal word nie. ${ }^{49}$ Dit moet egter duidelik en onomwonde gestel word dat die swaardmag die monopolie is van die staatsverband en nie van die owerheid nie, want owerhede mag wissel maar die staatsverband is onveranderlik. Indien enige privaat persoon of organisasie met politieke aspirasies die beheer in 'n staat wil oorneem, moet hy die beheer van die land se weermag in die hande kry. Die swaardmag moet gesien word as normatief en taakstellend in diens van die staatsverband in ooreenstemming met die Christelike opdrag soos onverbiddelik deur God gegee. Die mens moet binne die kader van daardie Goddellike Bevel optree, soos dit deur Gods Woordopenbaring bekend gemaak is. ${ }^{50}$ Daarom het somımige teorieë skipbreuk gely. So is in die fascistiese teorie van Mussolini51 geen plek vir die territoriale militêre organisasie nie. Hy was van mening dat deur sy sedelik-etiese staatsgedagte die swaardmag sy funderende funksie verloor het. Die praktyk en teorie het dit egter geloënstraf52 en daarom word sy diktatuur juis een van die swaard.

Soos aan die begin aangedui, het die staat nie slegs 'n funderingsfunksie nie maar ook 'n bestemmingsfunksie wat in die juridiese wetskring geleë is. Omdat die swaardmagorganisasie 'n spesifieke plek ten opsigte van die bestemmingsfunksie moet handhaaf, let ons nou op die bestemmingsfunksie as die bobou van die staat, sodat ons die militêre bestel kan tipeer binne die kader van sowel fundering as bestemming.

\section{Die bestemmingsfunksie van die staats- verband}

Die staatsverband vind sy bestemmingsfunksie (lei- dende of kwalifiserendel in die jurisdiese wetskring. Die grondwet van die jurisdiese wetskring is vergelding. ${ }^{53}$ Straf is maar net ' $n$ onderdeel hiervan. Binne die kring van die reg is daar natuurlik 'n verskeidenheid van regsoorte, soos byvoorbeeld; kerk-, huwelik-, gesins-, fabrieks,- verenigings- en staasreg. ${ }^{54}$

In onderskeiding van alle soorte nie-staatlike reg openbaar die staatsreg hom aan ons as 'n reg waarin vergelding die ewewigtige harmonie van die veelheid van regsbelange beteken, ${ }^{55}$ en juis hierdie verdiepte sin van vergelding plaas die stempel op die juridiese bestemmingsfunksie van die staatsverband. By die natuurvolk is daar - weens onontslotenheid en ongedifferensieerdheid - geen sprake van die verdiepte sin van die reg nie, maar dit bestaan wel by die kultuurvolk met ontplooide beskawing soos wat harmonie, en ewewig wat in die veelheid die ontslote sosiale, ekonomiese en estetiese lewe veronderstel. ${ }^{56}$

Kortom, reg en mag is die twee funksionele pole van die staatlike verbandstruktuur ${ }^{57}$ - die reg lei die mag, ${ }^{58}$ want die staat is ' $n$ regsverband. Hierdie staatlike verbandsreg is dan ook ' $n$ tipies heerskaplike verbandsreg van owerheid oor onderdaan ${ }^{59}$ gefundeer in die historiese swaardmag oor 'n begrensde territorium. Hierdie twee pole bepaal dan ook onder leiding van die juridiese bestemmingsfunksie - die funksie van die staat in alle ander wetskringe.

Soos hierbo gesê, is die tipiese bestemmingsfunksie, as strukturele kwalifikasie van die staat, slegs in die juridiese wetskring te vinde. Dit is derhalwe nodeloos om 'n ander leidende funksie te soek.

Wanneer ons in ag neem dat die staat in diens van die algemene belang staan, is dit vir ons duidelik waarom die staat se bestemmingsfunksie nie in sy territoriale swaadmagorganisasie geleë is nie. Die absolute ondergeskiktheid van die staat se ge-

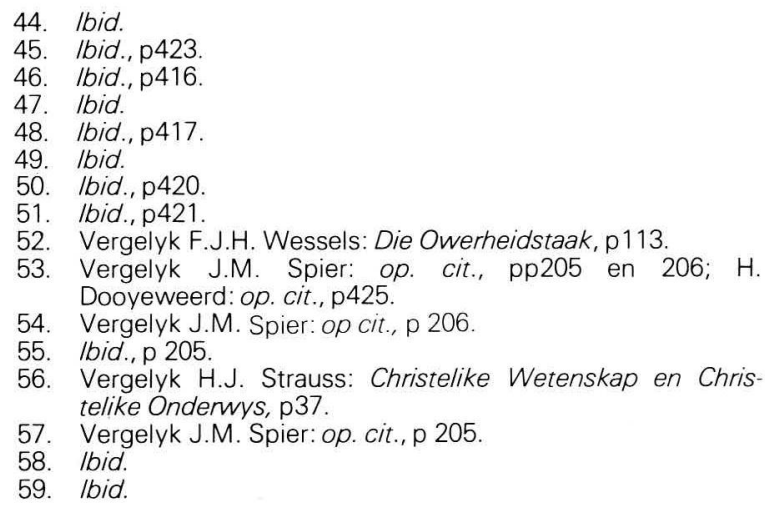

44. 1 bid.

8 lbid

o. Ibid., p420

Ibid. p421.

3. Vergelyk J.M. Spier: op. cit., pp205 en 206; H.

58. Ibid 
wapende magte aan sy owerheid is 'n vereiste vir die standvastigheid van die regsorde wat 'n uitstaande kenmerk van die staat is. 'n Tydelike delegasie van owerheidsgesag aan 'n militêre bevelvoerder is 'n noodmaatreël waarvan die staat slegs in tyd van oorlog en revolusie gebruik maak. ${ }^{60}$

In sy interne struktuur is die staat altyd onderdanig aan 'n bestendige en stabiele openbare regsorde, wat ook in die volkereg, die kriterium van die bestaan van die staat is.

Hierdie toestand word ook in 'n monopolisties georganiseerde gewapende mag weerspieël. Kelsen ${ }^{61}$ het byvoorbeeld met oortuiging daarop gewys dat enige poging om 'n staat anders as uit normatiefjuridiese oogpunt te skep tot mislukking gedoem is. Hy het die staat geïdentifiseer met 'n stelsel van regsnorme wat slegs verklaar kan word in die lig van die feit dat die juridiese aspek beslis 'n kwalifiserende posisie in die strukturele grondslag van die georganiseerde gemeenskap het. Dit is juis die verskil tussen die staat en alle ander gedifferensieerde lewensvorme met 'n nie-politieke karakter. Dit is wel waar dat laasgenoemde ook ' $n$ interne juridiese funksie het, maar dit is nie by hulle 'n leidende of kwalifiserende interne juridiese funksie nie. Soos reeds betoog, kan die staat sy kwalifiserende funksie in geen ander as die juridiese wetskring vind nie. Sonder hierdie leidende funksie sou die staat, as gevolg van sy tipiese funderingsfunksie, degenereer tot ' $n$ toestand van militêre bandeloosheid magspolitiek en staatsraison.

Hierdie aspek onderskei die staat radikaal van die nie-juridies-gekwalifiseerde georganiseerde samelewingsvorme soos byvoorbeeld kerk, gesin, skool en maatskappe. 62 Die staat se bestemmingsfunksie kan slegs in strukturele sin saam met sy tipiese funderingsfunksie begryp word. ${ }^{63}$ Die onverbreekbare interne strukturele samehang tussen reg en mag in die stateverhouding word veral in die struktuur van sy gesag uitgedruk. ${ }^{64}$ In teenstelling tot alle nie-politieke gemeenskapsverhouding, is gesag in die staat, in ooreenstemming met sy interne karakter, owerheidsgesag oor onderdane wat onder die gesag van die swaardmag staan. ${ }^{65}$

Die owerheid dra nie die swaard tevergeefs nie.66 Die owerheid is met die swaardmag beklee, en so- dra hierdie swaardmag uit sy hande glip, bestaan hy nie langer as 'n owerheid nie. Belangrik is dit egter om daarop te let dat die struktuur van die staatlike mag na binne gerig is op die strukturele leiding deur die tipiese juridiese bestemmingsfunksie waarvan die individualiteit in die beheer van die swaardmag geleë is. ${ }^{67}$ Alle interne gemeenskapsreg van die staat, in strukturele sin, is publieke gebiedsreg en wat deur die swaardmag gehandhaaf word. Al die wesentlike funksies van die staat behoort gerig te word deur die begrensde openbare juridiese gemeenskap, wat die 'politieke liggaam' kwalifiseer. ${ }^{68}$

'n Militêre heerser wat nie dié tipiese funksie van die staat verrig nie kan nooit 'n orgaan van die staat wees nie. Hy sal die leier van 'n georganiseerde militêre bende bly.

Aan die ander kant moet ons dit beklemtoon deur te herhaal dat die juridiese organisasie van die staat in sy tipiese gesagsverhouding onverbiddellik in die organisasie van die historiesbegrensde militêre reg gefundeer is. ${ }^{69}$ Daarsonder kan die interne publieke regsorde van die staat nie die tipiese juridiese karakter wat hom van alle soorte van privaatreg onderskei, openbaar nie. Dit sou foutief wees om te aanvaar dat hierdie interne publiekreg ' $n$ innerlike juridiese tipe individualiteit is, dit wil sê wat slegs deur sy eksterne verbintenis met die afdwingbare apparaat van die militêre mag uitgebeeld word

Ons konkludeer uit die voorafgaande uiteensetting van die normatiewe individualiteitstruktuur van die staat dat hierdie struktuur 'n gegewe van die skeppingsorde is en daarom is alle volke vir die positivering van hul staatlike lewe daaraan onderworpe. Teen hierdie agtergrond sien ons die staat as universele regsverband uittoring in elke gedifferensieerde samelewingsorde, en wat die owerheidstaak inderdaad duiseligwekkend maak.

60. Vergelyk H. Dooyeweerd: op. cit., p 434.
61. Ibid.
62. Ibid.
63. Ibid.
64. Ibid.
65. Ibid.
$6 \hat{6}$. ibid.
67. Ibid., p 435.
68. Ibid.
69. Ibid., p 436.

